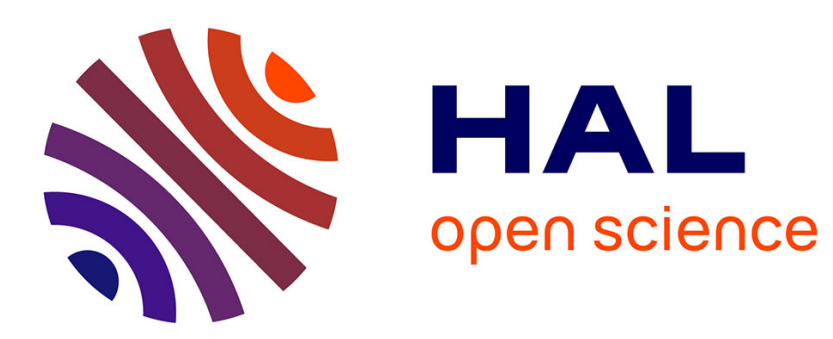

\title{
A dimensional analysis approach for modelling the size of droplets formed by bi-fluid atomization
}

Jérémy Petit, Serge Mejean, Philippe Accart, Laurence Galet, Pierre Schuck, Cécile Le Floch-Fouéré, Guillaume Delaplace, Romain Jeantet

\section{- To cite this version:}

Jérémy Petit, Serge Mejean, Philippe Accart, Laurence Galet, Pierre Schuck, et al.. A dimensional analysis approach for modelling the size of droplets formed by bi-fluid atomization. Journal of Food Engineering, 2015, 149, pp.237-247. 10.1016/j.jfoodeng.2014.10.022 . hal-01209745

\section{HAL Id: hal-01209745 \\ https://hal.science/hal-01209745}

Submitted on 26 Apr 2019

HAL is a multi-disciplinary open access archive for the deposit and dissemination of scientific research documents, whether they are published or not. The documents may come from teaching and research institutions in France or abroad, or from public or private research centers.
L'archive ouverte pluridisciplinaire HAL, est destinée au dépôt et à la diffusion de documents scientifiques de niveau recherche, publiés ou non, émanant des établissements d'enseignement et de recherche français ou étrangers, des laboratoires publics ou privés. 


\title{
A dimensional analysis approach for modelling the size of droplets formed by bi-fluid atomisation
}

\author{
Jeremy Petit ${ }^{\mathrm{a}, \mathrm{b}, \mathrm{c}, *}$, Serge Méjean ${ }^{\mathrm{b}, \mathrm{d}}$, Philippe Accart ${ }^{\mathrm{e}}$, Laurence Galet $^{\mathrm{e}}$, Pierre Schuck ${ }^{\mathrm{b}}$, \\ Cécile Le Floch-Fouéré $^{b}$, Guillaume Delaplace ${ }^{c}$, Romain Jeantet ${ }^{b}$ \\ ${ }^{a}$ Université de Lorraine, LIBio - Laboratoire d'Ingénierie des Biomolécules, 2, avenue de la Forêt de Haye, TSA 40602, 54518 Vandœuvre-lès-Nancy Cedex, France \\ ${ }^{\mathrm{b}}$ Agrocampus Ouest, INRA, UMR1253, Science et Technologie du Lait et de l'Euf, F-35000 Rennes, France \\ ${ }^{\mathrm{C}}$ INRA, U.R. 638 Processus aux Interfaces et Hygiène des Matériaux, F-59651 Villeneuve d'Ascq, France \\ ${ }^{\mathrm{d}}$ Bionov, 85, rue de Saint-Brieuc, 35042 Rennes Cedex, France \\ e Centre RAPSODEE, UMR CNRS 5302, Université de Toulouse, Ecole des Mines d'Albi-Carmaux, 81013 Albi Cedex 9, France
}

\begin{abstract}
A B S T R A C T
This paper presents a dimensional analysis (DA) ${ }^{\S}$ approach of the atomisation process using a bi-fluid nozzle, allowing to predict droplet sizes of model solutions and skimmed milk concentrates in large ranges of operating conditions. Experimental results confirmed the atomisation mechanism described in the literature, by underlining that the spraying operation is controlled by the coupling of liquid physicochemical properties (viscosity, surface tension, density) and operating conditions (air pressure and liquid flow rate). It was also highlighted that droplet coalescence occurs from a certain distance to the nozzle, counteracting the atomisation mechanism and leading to a reincrease in the droplet size when moving away from the nozzle. Consequently, the modelling of droplet size by DA was improved by adapting the model coefficients of the dimensionless process relationship to the involved mechanisms: either atomisation only close to the nozzle outlet or atomisation followed by droplet coalescence at longer distance to the nozzle.
\end{abstract}

\section{Keywords:}

Mathematical modelling

Bi-fluid nozzle

Liquid atomization

Droplet size

Coalescence

Operating conditions

\section{Introduction}

Wet agglomeration processes are used in the food industry to improve powder functionalities, such as wettability, solubility, and flowability. These processes involve the formation of liquid binder droplets by atomisation, which is a critical step, as it directly influences the wetting of fine powder particles and their ability to adhere one to each other and form agglomerates (Iveson et al., 2001; Litster and Ennis, 2004; Mandato et al., 2012; Saad, 2011). Besides, it has been evidenced that the droplet size produced by atomisation is highly correlated to the sizes of final particles in spray-drying and wet agglomeration processes (Cuq et al., 2013; Hede et al., 2008a; Iveson et al., 2001; JimenezMunguia, 2007; Leuenberger et al., 2006; Marmottant, 2001;

\footnotetext{
* Corresponding author at: Université de Lorraine, LIBio - Laboratoire d'Ingénierie des Biomolécules, 2 avenue de la Forêt de Haye, 54518 Vandœuvre-lès-Nancy Cedex, France. Tel.: +33 (0)3 835960 73; fax: +33 (0)3 83595804 .

E-mail addresses: jeremy.petit@univ-lorraine.fr (J. Petit), bionov.rennes@ wanadoo.fr (S. Méjean), accart@enstimac.fr (P. Accart), laurence.galet@mines-albi.fr (L. Galet), pierre.schuck@rennes.inra.fr (P. Schuck), cecile.lefloch@agrocampus-ouest. fr (C. Le Floch-Fouéré), guillaume.delaplace@lille.inra.fr (G. Delaplace), rjeantet@ agrocampus-ouest.fr (R. Jeantet).
}

Parikh, 2006). As a consequence, modelling droplet formation will help to better understand and characterise the mechanisms involved in spray-drying and wet agglomeration processes. The current study is in line with these concerns, as it aimed at developing a model by DA that allows the prediction of droplet size of different sprayed liquids in various operating conditions, with a particular emphasis on the evolution of droplet size with the distance to the nozzle outlet.

The general mechanism of liquid atomisation by bi-fluid nozzles is outlined below (Beau, 2006; Chigier, 1976; Hede et al., 2008a; Lefebvre, 1980; Mandato et al., 2012; Marmottant, 2001; Nguyen and Rhodes, 1998). Pumping the liquid through the nozzle results in the formation of a liquid jet at the nozzle outlet, which interacts with the surrounding atomising air at higher velocity. The air-liquid velocity difference causes high frictional forces on the liquid surface, inducing its deformation and the apparition of liquid filaments that are further disrupted into smaller and smaller droplets (Marmottant, 2001).

The influence of operating conditions on droplet size can be deduced from the above-mentioned mechanism. Increasing the air-liquid velocity difference at the nozzle outlet, either by lowering the liquid flow rate or raising the air pressure, results in smaller 


\begin{tabular}{|c|c|c|c|}
\hline \multicolumn{4}{|c|}{ Nomenclature } \\
\hline \multicolumn{2}{|c|}{$a_{j}$ for $j=0-6$ model coefficients $(-)$} & $T_{A}$ & air temperature (ambient, $18^{\circ} \mathrm{C}, 291.15 \mathrm{~K}$ ) \\
\hline & air orifice area $\left(\mathrm{m}^{2}\right)$ & $T_{L}$ & liquid temperature (ambient, $18{ }^{\circ} \mathrm{C}, 291.15 \mathrm{~K}$ ) \\
\hline & liquid orifice area $\left(\mathrm{m}^{2}\right)$ & $u_{A}$ & air velocity at the nozzle outlet $\left(\mathrm{m} \mathrm{s}^{-1}\right)$ \\
\hline$A R E_{\max }$ & maximal absolute relative error (\%) & $u_{L}$ & liquid velocity at the nozzle outlet $\left(\mathrm{m} \mathrm{s}^{-1}\right)$ \\
\hline & mean droplet diameter in volume (m) & We & aerodynamic Weber number $(-)$ \\
\hline$d_{50, \exp }$ & experimental droplet size $(\mathrm{m})$ & $\mu_{A}$ & air viscosity $\left(\mathrm{kg} \mathrm{m}^{-1} \mathrm{~s}^{-1}\right)$ \\
\hline$d_{50, \text { model }}$ & predicted droplet size $(\mathrm{m})$ & & liquid viscosity $\left(\mathrm{kg} \mathrm{m}^{-1} \mathrm{~s}^{-1}\right)$ \\
\hline & gravitational acceleration $\left(9.81 \mathrm{~m} \mathrm{~s}^{-2}\right)$ & \multirow{2}{*}{\multicolumn{2}{|c|}{$\begin{aligned} \pi_{i} \text { for } i= & 1-10 \text { dimensionless numbers obtained by dimensional } \\
& \text { analysis }(-)\end{aligned}$}} \\
\hline$L$ & distance to the nozzle outlet, i.e. distance from the noz- & & \\
\hline$\dot{m}_{A}$ & $\begin{array}{l}\text { zle outlet at which the droplet size was measured (m) } \\
\text { air mass flow rate }\left(\mathrm{kg} \mathrm{s}^{-1}\right)\end{array}$ & $\pi_{T}$ & $\begin{array}{l}\text { target dimensionless number, i.e. dimensionless droplet } \\
\text { size }(-)\end{array}$ \\
\hline & liquid mass flow rate $\left(\mathrm{kg} \mathrm{s}^{-1}\right)$ & $\sigma$ & liquid surface tension $\left(\mathrm{kg} \mathrm{s}^{-2}\right)$ \\
\hline MARE & mean absolute relative error (\%) & $\rho_{A}$ & air density $\left(\mathrm{kg} \mathrm{m}^{-3}\right)$ \\
\hline NMRSE & normalised mean root squared error (\%) & $\rho_{L}$ & liquid density $\left(\mathrm{kg} \mathrm{m}^{-3}\right)$ \\
\hline & Ohnesorge number (-) & $\varphi_{A, i n t}$ & air orifice internal diameter (3.4 mm) \\
\hline & relative air pressure $(\mathrm{Pa})$ & $\varphi_{A, \text { ext }}$ & air orifice external diameter (4.8 mm) \\
\hline & air volumetric flow rate $\left(\mathrm{m}^{3} \mathrm{~s}^{-1}\right)$ & $\varphi_{L}$ & liquid orifice diameter (0.8 mm) \\
\hline$Q_{L}$ & liquid volumetric flow rate $\left(\mathrm{m}^{3} \mathrm{~s}^{-1}\right)$ & & \\
\hline
\end{tabular}

droplets. Several literature studies confirmed this trend (Chigier, 1976; Nguyen and Rhodes, 1998; Nukiyama and Tanasawa, 1939; Lefebvre, 1980); furthermore, it was pointed out that air pressure is a crucial process parameter in the atomisation operation (Chigier, 1976; Ehlers et al., 2010; Hede et al., 2008a; Juslin et al., 1995; Lefebvre, 1980; Mandato et al., 2012; Nguyen and Rhodes, 1998).

The geometrical features of the nozzle are also linked to fluid velocities at the nozzle outlet (Cuq et al., 2013; Mandato et al., 2012). At constant liquid and air flow rates, the larger the air orifice area and/or the smaller the liquid orifice area, the lower the airliquid velocity difference at the nozzle outlet, and thus the larger the droplets.

The influence of physicochemical properties of sprayed liquids is more intricate to evaluate, owing to their interactions with operating parameters. The main physicochemical properties (viscosity, surface tension, and density), jointly varying when changing the liquid composition, are related to the ability of the liquid phase to resist break-up by frictional forces (Hede et al., 2008a; Lefebvre, 1980; Mandato et al., 2012; Marmottant, 2001).

Viscosity gauges the ability of a fluid to resist deformation by shear stress; thus, it is expected to moderate the impact of frictional forces in the atomisation mechanism. Even though a marked increase of droplet size is expected at higher viscosity and has been evidenced for some nozzle geometries (Ejim et al., 2010; Hede et al., 2008a; Lefebvre, 1980; Nukiyama and Tanasawa, 1939), the recent experiments carried out by Mandato et al. (2012) on model solutions did not permit to conclude about the influence of viscosity on liquid atomisation with bi-fluid nozzles. Indeed, opposite trends were found depending on the value of liquid surface tension, presumably owing to the control of the atomisation process by operating conditions rather than liquid physicochemistry.

Surface tension is known to characterise the resistance of a liquid surface to stretching, and thus is opposed to the creation of new liquid surfaces subsequent to droplet formation. This has been evidenced with low viscosity liquids $(\approx 1 \mathrm{MPa} s)$ like water (Chigier, 1976; Hede et al., 2008a; Lefebvre, 1980; Mandato et al., 2012), but it seems that the influence of surface tension becomes negligible at high viscosity when using bi-fluid nozzles (Lefebvre, 1980; Mandato et al., 2012).

Last, the complex influence of liquid density on droplet size has not totally been elucidated yet. Hede et al. (2008a) suggest that high density liquids produce more compact sprays that are less exposed to frictional forces, resulting in larger droplets. This was experimentally evidenced by Hede et al. (2008a), Lefebvre (1980), and the process relationship proposed by Mandato et al. (2012).

Droplet size is also expected to be greatly affected by the distance to the nozzle outlet (Cuq et al., 2013; Ehlers et al., 2010; Mandato et al., 2012), as the atomisation mechanism produces liquid elements that decrease in size when moving away from the nozzle outlet: first, liquid jet; then, liquid ligaments and large droplets; finally, small droplets (Marmottant, 2001). However, other phenomena take part in the shaping of droplets, like droplet coalescence that forms larger droplets and thus counteracts the atomisation mechanism. Differences in size and velocity within the droplet population may result in droplet collision and coalescence, mainly depending on the droplet surface tension (Ehlers et al., 2010). Therefore, close to the nozzle outlet, where the atomisation mechanism predominates, the droplet size is expected to decrease with the distance to the nozzle. Then, under the increasing influence of the coalescence mechanism when moving away from the nozzle, an attenuation of the droplet size decrease or even a reincrease in the droplet size can occur (Lefebvre, 1980).

In order to address this phenomenological complexity, a semiempirical modelling approach by DA seems appropriate, as DA is an interesting process engineering tool that has recently showed efficiency in modelling food processes involving numerous process parameters (Delaplace et al., 2012; Hassan et al., 2012; Petit et al., 2013). Also, the suitability of DA for modelling liquid atomisation by mono- and bi-fluid nozzles was demonstrated by the pioneer work of Mandato et al. (2012).

In the literature, diverse empirical relationships adapted to various nozzle designs (mono- or bi-fluid, internal or external mixing) have been proposed (Hede et al., 2008a; Jimenez-Munguia, 2007; Lefebvre, 1980; Nguyen and Rhodes, 1998), but they suffer from some limitations (Hede et al., 2008a) that preclude their direct application to the atomisation of food liquids:

- experimental data were obtained with model solutions only (water, aqueous solutions of glycerol, kaolin suspensions, etc.) in narrow ranges of operating conditions,

- a very small number of process parameters was explicitly considered; unfortunately, the distance to the nozzle was rarely one of those. 
Although these empirical relationships have generally been established without considering all the underlying mechanisms, they often include some relevant dimensionless numbers of the atomization operation, which might be helpful to perform the complete DA approach of the current study. Nozzle geometry was considered through the dimensionless ratio between the size or area of air and liquid orifices. Liquid viscosity and density were ratioed to the similar air properties (Nguyen and Rhodes, 1998), whereas surface tension was often considered through the Ohnesorge number Oh (Lefebvre, 1980; Nguyen and Rhodes, 1998), comparing the viscous, inertial, and surface tension forces acting on the liquid jet:

$O h=\frac{\mu_{L}}{\varphi_{L}^{0.5} \rho_{L}^{0.5} \sigma^{0.5}}$

Surface tension and liquid viscosity can also be dissociated by using the Bond number Bo (Eq. (2)), which is relevant for freesurface flows, as it is related to surface tension, gravity, and buoyancy forces (Hager, 2012; Zlokarnik, 2006).

Bo $=\frac{\left(\rho_{L}-\rho_{A}\right) g \varphi_{L}^{2}}{\sigma}$

The air-to-liquid ratio $A L R$, defined as the ratio between air and liquid mass flow rates (Eq. (3)), has often been cited as a dimensionless quantity representative for the atomisation operating conditions (Lefebvre, 1980).

$A L R=\frac{\dot{m}_{A}}{\dot{m}_{L}}=\frac{\rho_{A} u_{A} A_{A}}{\rho_{L} u_{L} A_{L}}$

$A L R$ is well correlated to the droplet size: higher $A L R$ values lead to smaller droplets, as $A L R$ increases when air velocity increases or liquid velocity decreases (Chigier, 1976; Hede et al., 2008a; Nguyen and Rhodes, 1998). Moreover, this process parameter has been successfully employed by Hede et al. (2008b) to scale-up particle coating processes on the basis of the droplet size, which shows its relevance in a DA approach.

Equally, many authors proposed to model the role of operating conditions with the aerodynamic Weber number We (Eq. (4)), which compares frictional and surface tension forces (Lefebvre, 1980; Marmottant, 2001; Nguyen and Rhodes, 1998), and thus relates operating conditions to liquid physicochemistry.

$W e=\frac{\rho_{A}\left(u_{A}-u_{L}\right)^{2} \varphi_{L}}{\sigma}$

When We is increased, the atomisation mechanism becomes more intense and the resulting droplets are smaller (Faragó and Chigier, 1992). Last, the aerodynamic Weber number allows characterising the regime of droplet formation in atomisation processes and should be integrated in atomisation models (Marmottant, 2001).

The first purpose of the current study was to develop a DA approach enabling to link in a single process relationship the droplet size to the physicochemical characteristics of inlet liquid and air, operating conditions, and geometrical features of the atomisation system. Therefore, various model solutions and skimmed milk concentrates were sprayed to investigate the roles of surface tension, viscosity, and density; air pressure and liquid flow rate were varied to determine the influence of operating conditions; and two measurement distances were tested. To achieve the modelling of droplet size, we propose to extend the DA approach of Mandato et al. (2012) by integrating all the dimensionless numbers involved in the atomisation process, not only those arising from droplet fragmentation in the vicinity of the nozzle outlet, as formulated in Cuq et al. (2013).

This enhanced DA approach is expected to shed light on the dependency of the atomisation and coalescence mechanisms on the distance to the nozzle, but also to compare the respective roles of physicochemistry and operating conditions.

In brief, this study aims at addressing the following questions through the developed DA approach:

- Are the classically considered liquid physicochemical properties (surface tension, viscosity, and density) sufficient to describe the atomisation of complex liquids of biological origin such as skimmed milk concentrates?

- How does the distance to the nozzle impact on the droplet size?

- What is the contribution of droplet coalescence in the atomisation process?

- Far from the nozzle outlet, are the operating conditions still predominant over the physicochemistry of the inlet liquid?

\section{Material and methods}

\subsection{Sprayed liquids}

In order to investigate the role of physicochemical properties (density, viscosity, surface tension), atomisation experiments were performed with model solutions and skimmed milk concentrates (Table 1).

Model solutions were prepared by mixing different amounts of deionised water, ethanol, and glycerol. The ethanol content permitted to adjust the surface tension, whereas glycerol was used to tune the viscosity of model solutions, as in Mandato et al. (2012). Four compositions of these ternary mixtures were selected from the work of Mandato et al. (2012) in order to vary surface tension at low and high viscosity (Table 1a). The viscosity and density values reported in Table $1 \mathrm{a}$ correspond to the measurements performed at ambient temperature $T_{L}=18^{\circ} \mathrm{C}$ by Mandato et al. (2012). Surface tension was determined with a Krüss K100 tensiometer (Krüss, Germany) using the Wilhelmy plate method at ambient temperature $\left(T_{L}=18^{\circ} \mathrm{C}\right)$ by averaging ten replicated analyses.

Skimmed milk concentrates of $30 \%, 35 \%$, and $40 \%(\mathrm{w} / \mathrm{w})$ total solids (Table $1 \mathrm{~b}$ ) were prepared by rehydration of the adequate mass of skimmed milk powder (medium heat, Lactalis, France). Powder suspensions were stirred at $1500 \mathrm{rpm}$ with a deflocculating blade (42 mm diameter, IKA, Germany) at $40{ }^{\circ} \mathrm{C}$ during $1 \mathrm{~h}$, until complete powder dissolution that was checked with a refractometer (28-62\% Brix, Master-2M, Atago, Japan). The very few undissolved powder was removed by sieving at $500 \mu \mathrm{m}$. Skimmed milk concentrates were then stored overnight at $4{ }^{\circ} \mathrm{C}$ in order to allow removal of air bubbles introduced during the stirring process. Before atomisation experiments, skimmed milk concentrates were gently heated up to $18{ }^{\circ} \mathrm{C}$ and their pH was checked with a PHM 210 pH-meter (Radiometer Analytical, France) to ensure microbial stability during night storage.

The physicochemical properties of skimmed milk concentrates were evaluated at ambient temperature $\left(T_{L}=18^{\circ} \mathrm{C}\right.$, Table $\left.1 \mathrm{~b}\right)$. Viscosity was measured with an AR1000 rheometer (TA Instruments - Waters, France) supplied with concentric cylinders of $5 \mathrm{~mm}$ gap according to the following protocol: shear rate was varied from 0.1 to $500 \mathrm{~s}^{-1}$ by using a logarithmic gradient of $30 \mathrm{~s}$ duration. Viscosity values displayed in Table $1 \mathrm{~b}$ were the mean of four measurements averaged between 100 and $500 \mathrm{~s}^{-1}$ shear rate. As displayed in Table 1, the increase in total solids of skimmed milk concentrates led to higher viscosity at almost constant surface tension. Viscosity, surface tension, and density values of skimmed milk concentrates were all comprised in the investigated ranges of model solutions, except the viscosity at $40 \%(\mathrm{w} / \mathrm{w})$ total solids that was slightly higher.

Surface tension was measured with the same protocol as for ternary mixtures. Density was calculated from the density values 
Table 1

(a) Composition, viscosity, surface tension, and density of model solutions; (b) total solids, viscosity, surface tension, density, and pH of skimmed milk concentrates. MS1 to MS4: model solutions; SMC1 to SMC3: skimmed milk concentrates.

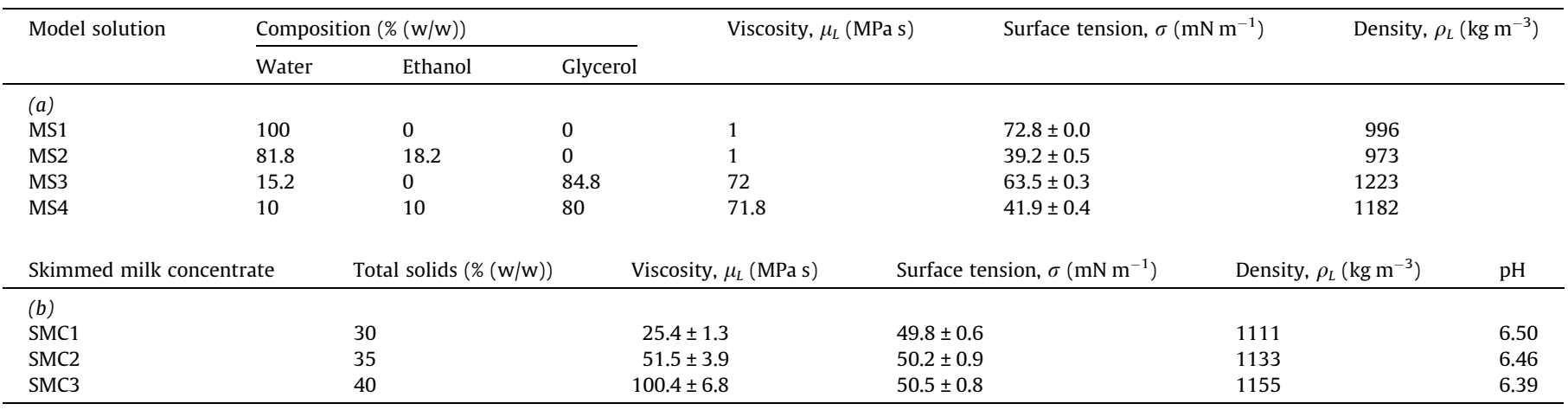

of pure water $\left(996 \mathrm{~kg} \mathrm{~m}^{-3}\right.$ at $\left.18{ }^{\circ} \mathrm{C}\right)$ and skimmed milk powder (true density of $1520 \mathrm{~kg} \mathrm{~m}^{-3}$ ) by assuming volume additivity as reported by Jeantet et al. (2001).

\subsection{Nozzle characteristics and operating conditions}

In atomisation experiments, operating conditions were investigated by varying the air pressure and the liquid volumetric flow rate, while keeping the air and liquid temperatures at ambient $\left(T_{A}=T_{L}=18^{\circ} \mathrm{C}\right)$ in order to fix the physicochemical properties of spraying air and each sprayed liquid. Experiments took place in a positive-pressure room ( $+50 \pm 10$ Pa relative pressure) at constant temperature $\left(18{ }^{\circ} \mathrm{C}\right)$ in order to ensure the fast evacuation of produced sprays.

Empty cone sprays were produced with an external mixing bifluid nozzle (GEA Niro, Denmark) of fixed geometrical features: $0.8 \mathrm{~mm}$ liquid orifice diameter; $3.4 \mathrm{~mm}$ (internal) and $4.8 \mathrm{~mm}$ (external) air orifice diameters.

The employed compressed air was dehumidified and thermostated to maintain $20 \pm 5 \%$ relative humidity and $18{ }^{\circ} \mathrm{C}$. Air viscosity at $18^{\circ} \mathrm{C}$ was evaluated at $1.8 \times 10^{-5} \mathrm{~kg} \mathrm{~m}^{-1} \mathrm{~s}^{-1}$ with Sutherland's law (White, 1991). Air density, calculated with the correlation $353 / T_{A}$ (Jeantet et al., 2001) with $T_{A}=291.15 \mathrm{~K}$, was found to be $1.21 \mathrm{~kg} \mathrm{~m}^{-3}$.

The first group of spraying experiments consisted in measuring the droplet size of model solutions and skimmed milk concentrates at various air velocities (between 152 and $356 \mathrm{~m} \mathrm{~s}^{-1}$ ) and fixed liquid velocity (either $u_{L}=1.33 \mathrm{~m} \mathrm{~s}^{-1}$ for MS1, MS2, SMC1, SMC2, SMC3 or $1.03 \mathrm{~m} \mathrm{~s}^{-1}$ for MS3 and MS4). Air velocity was adjusted by varying the atomisation air relative pressure between 0.5 and 2.5 bar by 0.5 bar steps with an air pressure regulator (SC 602, Taiyo Parker, China) and a manometer (Tempress, Denmark). Air mass flow rate was also measured with a flow meter (H250 RR/M9 ESK, Khrone, Germany), and a linear relationship between relative air pressure and mass flow rate was evidenced by carrying out measurements in triplicate at five relative air pressures $\left(R^{2}=99.9 \%\right.$, Eq. (5)):

$\dot{m}_{A}=1.11 \times 10^{-3}\left(P_{A}+1\right)$

Finally, the mean air velocity at the nozzle outlet was calculated with the following formula (Eq. (6)), owing to the annular shape of the air orifice:

$u_{A}=\frac{4 \cdot \dot{m}_{A}}{\rho_{A} \cdot \pi\left(\varphi_{A, \text { ext }}^{2}-\varphi_{A, \text { int }}^{2}\right)}$

The investigated air velocities ranged between 152 and $356 \mathrm{~m} \mathrm{~s}^{-1}$.
The second group of spraying experiments concerned the study of the influence of liquid velocity at fixed air velocity $\left(u_{A}=\right.$ $254 \mathrm{~m} \mathrm{~s}^{-1}$, corresponding to $P_{A}=1.5$ bar). Various liquid velocities were investigated by adjusting the liquid volumetric flow rate with a peristaltic pump (520S, Watson-Marlow, UK) so as to limit the Venturi effect at the nozzle outlet. By using a graduated polypropylene cylinder of $500 \mathrm{~mL}$ (VWR international, Radnor, USA) and a stopwatch, flow rate calibration (data not shown) was achieved in triplicate for each sprayed liquid at $P_{A}=1.5$ bar and ambient temperature $T_{L}=18^{\circ} \mathrm{C}$. Also, it was checked that liquid flow rate was not significantly affected by air pressure by performing the same calibration method at $P_{A}=0.5$ and 2.5 bar once for each fluid (data not shown).

Achievable liquid flow rates (and velocities at the nozzle outlet) depended on liquid viscosity:

- for MS1, MS2, SMC1, SMC2, liquid flow rate was varied between

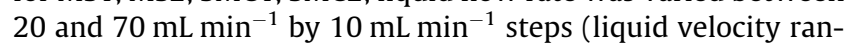
ged from 0.7 to $2.3 \mathrm{~m} \mathrm{~s}^{-1}$ ),

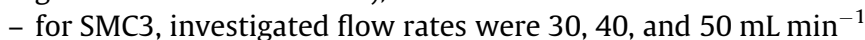
(liquid velocity varied from 1 to $1.7 \mathrm{~m} \mathrm{~s}^{-1}$ ),

- and for MS3 and MS4, liquid flow rate was adjusted between 15.5 and $54.5 \mathrm{~mL} \mathrm{~min}^{-1}$ by $7.8 \mathrm{~mL} \mathrm{~min}^{-1}$ steps (liquid velocity was comprised between 0.5 and $1.8 \mathrm{~m} \mathrm{~s}^{-1}$ ).

\subsection{Droplet size measurement}

Once for each combination of operating conditions, sprayed liquid, and distance to the nozzle, the mean droplet size was measured by laser diffraction with a Spraytec apparatus (Malvern, UK). The experimental configuration was the same as in Mandato et al. (2012): the laser beam perpendicularly crossed the axis of symmetry of the empty cone spray produced by the bi-fluid nozzle, which permitted size measurements of droplets located at the same distance to the nozzle outlet. It was checked that the droplet size distribution was not affected by the angular displacement of the bi-fluid nozzle.

Accurate droplet size determinations (relative standard deviation in a single analysis inferior to $5 \%$ ) were ensured by performing analyses during one minute over $90 \%$ light transmission. In this study, the chosen size estimator was the mean diameter in volume $d_{50}$, as it was previously shown in similar experimental conditions (Mandato et al., 2012) and checked in this work (data not shown) that droplet size distributions were monomodal; hence, for these experiments, all size estimators were correlated and a single one was sufficient to represent the whole size distribution: the classical mean diameter in volume $d_{50}$ was chosen here.

In this study, the influence of the distance to the nozzle on droplet size was investigated by carrying out droplet size measurement 
at two distances to the nozzle outlet: at $L=14 \mathrm{~cm}$, like in Mandato et al. (2012), corresponding to the typical length between nozzle outlet and powder bed in pilot-scale fluidised bed granulators, and at $L=5 \mathrm{~cm}$, corresponding to the distance at which powder particles and droplets meet when recycling fine particles at the top of spraydryers for agglomeration purposes.

\subsection{Dimensional analysis of the atomisation process}

A DA of the atomisation process was carried out in order to build a dimensionless process relationship between investigated process parameters and droplet size. A DA approach generally comprises five steps (Delaplace et al., 2014): listing of all influent process parameters, establishment of dimensionless numbers (for instance with the dimensional matrix method), algebraic combinations of these numbers into characteristic numbers of the studied process (here, atomisation), proposition of a mathematical form for the dimensionless process relationship (generally, monomial), and determination of model coefficients with a model fitting tool.

\subsubsection{Listing of relevant process parameters}

The target parameter, mean droplet diameter in volume $d_{50}$, is impacted by all the process parameters taking part in the atomisation process. The process parameters can be sorted into three categories:

\section{- System properties:}

- The geometry of the bi-fluid nozzle is characterised by the liquid and air orifice diameters, $\varphi_{L}, \varphi_{A, \text { int }}$, and $\varphi_{A, \text { ext }}$;

- System configuration is defined by the distance to the nozzle, $L$.

- Physicochemistry of sprayed liquids and atomisation air:

- Liquid properties: viscosity, $\mu_{\mathrm{L}}$, surface tension, $\sigma$, and density, $\rho_{L}$;

- Air properties: viscosity, $\mu_{A}$, and density, $\rho_{A}$.

- Operating conditions:

- Liquid and air velocities at the nozzle outlet, respectively $u_{L}$ and $u_{A}$;

- Gravitational acceleration, $g$.

Contrary to Mandato et al. (2012), the air velocity was considered instead of its relative pressure, as it is representative for the driving force of the atomisation mechanism while being independent of nozzle geometry. For the same reason, liquid velocity at the nozzle outlet was taken into account instead of its flow rate. Gravitational acceleration was added to the list of relevant process parameters, as it may impact the free-surface flow of the liquid jet.

From the list of relevant process parameters in the atomisation process, it can be stated that a process relationship of the following form exists (Eq. (7)):

$d_{50}=f\left(\varphi_{L}, \varphi_{A, \text { int }}, \varphi_{A, \text { ext }}, L, \mu_{L}, \sigma, \rho_{L}, \mu_{A}, \rho_{A}, u_{L}, u_{A}, g\right)$

\subsubsection{Determination of relevant dimensionless numbers}

The key process parameters identified in Eq. (7) were turned into dimensionless numbers by using the $\pi$-theorem (Buckingham, 1914; Vaschy, 1892). To this end, the dimensional matrix method was employed (Delaplace et al., 2014), like in Mandato et al. (2012). 3 physical dimensions (mass, length, time) being sufficient to express the target parameter and the 12 process parameters of Eq. (7), the atomisation process can be completely described by (12 (process) +1 (target) -3 (dimensions)) 10 dimensionless numbers. $L, \mu_{A}$, and $g$, gathering the 3 physical dimensions, were chosen as reference parameters to form the dimensionless numbers. Indeed, $\mu_{\mathrm{A}}$ and $g$ did not vary in our experiments. Moreover, $L$ was included in the reference parameters because it has been identified by Mandato et al. (2012) as the key geometric parameter in liquid atomisation and it took only two different values in the current experimental setup. As a result of the dimensional matrix method, the dimensionless numbers corresponding to the target parameter $\left(\pi_{T}\right)$ and key process parameters ( $\pi_{i}$ for $i$ varying between 1 and 10 ) were listed in Eq. (8):

$\left\{\pi_{T}=\frac{d_{50}}{L}, \pi_{1}=\frac{\varphi_{L}}{L}, \pi_{2}=\frac{\varphi_{A, i n t}}{L}, \pi_{3}=\frac{\varphi_{A, \text { ext }}}{L}, \pi_{4}=\frac{\mu_{L}}{\mu_{A}}, \pi_{5}=\frac{\sigma}{\mu_{A} L^{0.5} g^{0.5}}\right.$

$\left.\pi_{6}=\frac{\rho_{L}}{\mu_{A} L^{-1.5} g^{-0.5}}, \pi_{7}=\frac{\rho_{A}}{\mu_{A} L^{-1.5} g^{-0.5}}, \pi_{8}=\frac{u_{L}}{L^{0.5} g^{0.5}}, \pi_{9}=\frac{u_{A}}{L^{0.5} g^{0.5}}\right\}$

\subsubsection{Definition of the dimensionless process relationship}

The set of dimensionless numbers of Eq. (8) was rearranged by algebraic combinations of dimensionless numbers in order to:

- reduce the set of dimensionless numbers by forming constant ratios with regard to the experimental program, which can be removed from Eq. (8). Given that a unique bi-fluid nozzle was employed, only one geometrical ratio was needed ( $\pi_{1}$ was chosen): $\pi_{2}$ and $\pi_{3}$ were removed as they could respectively be replaced by $\pi_{1}^{-1} \pi_{2}=\frac{\varphi_{\text {A.int }}}{\varphi_{L}}$ and $\pi_{1}^{-1} \pi_{3}=\frac{\varphi_{\text {A.ext }}}{\varphi_{L}}$. In the same way, the physicochemical air properties remained constant as inlet temperatures were fixed, so $\pi_{7}$ was removed by applying the following combination, leading to a constant ratio: $\pi_{1}^{1,5} \pi_{7}=\frac{\varphi_{L}{ }^{1,5} \rho_{A}}{\mu_{A} g^{-0,5}}$.

- form dimensionless numbers depending solely on matter properties: $\pi_{2}$ already ratioed liquid and air viscosities, while the ratio between liquid and air densities can be obtained by replacing $\pi_{6}$ by $\pi_{6} \pi_{7}^{-1}=\frac{\rho_{L}}{\rho_{A}}$.

- rewrite the dimensionless numbers related to operating conditions into the dimensionless numbers most widely used to describe the atomisation mechanism (cf. Eqs. (2)-(4)):

- $W e=\pi_{1} \pi_{5}^{-1} \pi_{7}\left(\pi_{9}-\pi_{8}\right)^{2}$,

- $A L R=\frac{\rho_{\rho_{A} u_{A} A_{A}} A_{L} A_{L}}{A_{L}}=\pi_{1}^{-2}\left(\pi_{3}^{2}-\pi_{2}^{2}\right) \pi_{6}^{-1} \pi_{7} \pi_{8}^{-1} \pi_{9}$, where $\quad A_{A}=$ $\frac{\pi\left(\varphi_{A, \text { ext }}^{2}-\varphi_{A, \text { int }}^{2}\right)}{4}$ and $A_{L}=\frac{\pi \varphi_{L}^{2}}{4}$ stand respectively for the air and liquid orifice areas,

- $B o=\pi_{1}^{2} \pi_{5}^{-1}\left(\pi_{6}-\pi_{7}\right)$.

According to the reduced set of relevant dimensionless numbers, a dimensionless process relationship in the monomial form of Eq. (9) was searched in this study:

$\frac{d_{50}}{L}=a_{0}\left(\frac{\varphi_{L}}{L}\right)^{a_{1}}\left(\frac{\mu_{L}}{\mu_{A}}\right)^{a_{2}}\left(\frac{\rho_{L}}{\rho_{A}}\right)^{a_{3}} B 0^{a_{4}} W e^{a_{5}} A L R^{a_{6}}$

This dimensionless process relationship allows considering the influence of the distance to the nozzle separately from the other process parameters (as $L$ is only found in $\pi_{T}$ and $\pi_{1}$ ).

\subsubsection{Model fitting procedure and validation}

The model coefficients of the dimensionless process relationship were determined with Excel 2010 solver (Microsoft, Redmond, USA) and the XLSTAT add-on (Addinsoft, Paris, France) by performing a logarithmic transformation of Eq. (9) and then using multilinear regression of the 134 experimental points (one for each liquid, distance to the nozzle, liquid flow rate, and air pressure) with least squares method. Statistical analysis was carried out with XLSTAT at 95\% confidence level in order to check the relevance of model 
coefficients by Shapiro-Wilk and Student tests (i.e., normal distribution of errors around a mean value that is not statistically different from 0 ). These statistical results were represented by a $p$-value ( $p$-value $>0.05$ signifies that the associated model coefficient is not relevant, i.e. not statistically different from 0 ). Also the coefficient of determination $R^{2}$ of Eq. (9) (in native form) was calculated to gauge the goodness of fit.

Models derived from Eq. (9) were validated by determining the prediction error on 14 unknown samples, corresponding to one analysis for each sprayed liquid at the two investigated distances to the nozzle in intermediate operating conditions:

- $Q_{L}=40 \mathrm{~mL} \mathrm{~min}^{-1}$ and $P_{A}=1.5$ bar for MS1, MS2, SMC1, SMC2, SMC3,

$-Q_{L}=31.2 \mathrm{~mL} \mathrm{~min}^{-1}$ and $P_{A}=1.5$ bar for MS3 and MS4.

The prediction errors were evaluated by calculating on one hand the mean and maximal absolute relative errors for the 134 points of the experimental setup, respectively abbreviated MARE and $A R E_{\max }$, and on the other hand, the normalised root mean square error for the 14 unknown samples, noted NRMSE and calculated with Eq. (10):

$N R M S E=\sqrt{\frac{\sum\left(d_{50, \exp }-d_{50, \text { model }}\right)^{2}}{\sum d_{50, \text { exp }}}}$

where $\sum\left(d_{50, \text { exp }}-d_{50 \text {,model }}\right)^{2}$ is the sum of squared errors between model predictions $\left(d_{50, \text { model }}\right)$ and experimental values of unknown samples $\left(d_{50, \text { exp }}\right)$, and $\sum d_{50 \text {,exp }}$ represents the sum of experimental droplet sizes of unknown samples.

\section{Results and discussion}

On one hand, raw experimental results will be discussed to verify if the atomisation mechanism presented in the introduction permits to understand the evolution of the droplet size with process parameters. A particular emphasis will be put on the influence of the distance to the nozzle, as it was evidenced in the literature that droplet coalescence could occur and counteract the atomisation mechanism from a certain distance to the nozzle outlet.

On the other hand, the statistical significance of the model coefficients of the dimensionless process relationship (Eq. (9)) and the model accuracy will be discussed. From these considerations, an improved modelling approach will be presented and discussed. This will allow to better understand how the impact of each process parameter on the droplet size is affected by the distance to the nozzle.

\subsection{Experimental results}

Fig. 1 presents the droplet size obtained for model solutions by varying the air pressure at constant liquid flow rate (Fig. 1a and b), and inversely by changing the liquid flow rate at constant air pressure (Fig. 1c and d). Fig. 2 displays the droplet size of skimmed milk concentrates either at variable air pressure (Fig. 2a and b) or liquid flow rate (Fig. 2c and d).

\subsubsection{Impact of liquid physicochemical properties (viscosity and} surface tension) on the droplet size

Viscosity is expected to decrease the droplet size, as it is opposed to the break-up of the liquid jet during the atomisation mechanism. This was confirmed with model solutions whatever the surface tension, liquid flow rate, and air pressure: droplet sizes of MS4 were systematically higher than those of MS2 (especially in Fig. 1a and b), whereas MS3 droplets were larger than those of MS1 (cf. Fig. 1b-d). Also, the increase in droplet size at higher viscosity, evidenced for model solutions, was still verified with the skimmed milk concentrates (cf. Fig. 2c and d in which SMC3 droplets were systematically larger than SMC1 and SMC2 ones). High surface tension values seemed to lower the influence of viscosity (cf. Fig. 1c and $\mathrm{d}$, in which the difference between MS2 and MS4 droplet size was rather small), confirming the complex relation between viscosity and surface tension in atomisation processes, already highlighted by Mandato et al. (2012). Flow rate did not seem to alter the influence of viscosity on the droplet size (cf. Fig. 1c and d), but air pressure tended to markedly reduce the influence of viscosity, especially close to the nozzle outlet (cf. the close droplet sizes of model solutions at $P_{A}=2.5$ bar and $L=5 \mathrm{~cm}$ in Fig. 1 a). This could be an indication of the predominance of air pressure in droplet shaping close to the nozzle outlet. Also, an intensification of the role of viscosity in the droplet size when increasing the distance to the nozzle was denoted: droplet sizes were approximately found in the $10-40 \mu \mathrm{m}$ range at $L=5 \mathrm{~cm}$ (Fig. $1 \mathrm{a}-\mathrm{c}$ ) and in the $10-70 \mu \mathrm{m}$ range at $L=14 \mathrm{~cm}$ (Fig. $1 \mathrm{~b}-\mathrm{d}$ ). This result may signify that liquid physicochemistry had more influence on the droplet size far from the nozzle outlet.

The impact of surface tension on droplet size strongly depended on liquid viscosity. Whatever the distance to the nozzle, surface tension induced a strong increase in droplet size at low viscosity (Fig. 1a and b), but its role was unclear at high viscosity, as close droplet sizes were systematically obtained for MS3 and MS4. This observation is consistent with the work of Mandato et al. (2012), who showed that surface tension has almost no influence on the droplet size of highly viscous liquids when using a bi-fluid nozzle, contrary to solutions at low viscosity. No clear evidence of interactions between operating conditions and surface tension could be evidenced with acquired results. The influence of surface tension on the droplet size was increased when moving away from the nozzle, similarly to viscosity. In conclusion, this implies that, far from the nozzle outlet, liquid physicochemistry gains influence in droplet formation to the detriment of operating conditions, suggesting that an additional mechanism driven by liquid physicochemistry takes place between $L=5$ and $14 \mathrm{~cm}$.

\subsubsection{Influence of operating conditions in the atomisation process}

Regardless of the sprayed liquid and distance to the nozzle, an increase in liquid flow rate resulted in moderately larger droplets (cf. Figs. 1, 2c and d). This is consistent with the atomisation mechanism, as the driving force for liquid jet break-up is reduced when decreasing the air-liquid velocity difference (e.g., when increasing liquid velocity, as $u_{A} \gg u_{L}$ with bi-fluid nozzles). Besides, liquid flow rate had a similar influence on the droplet size whatever the distance to the nozzle and the sprayed liquid, which confirmed that the atomisation mechanism is mainly controlled by operating conditions, particularly close to the nozzle. For example, it can be noted that SMC1 and SMC2, having different viscosity values, led to similar droplet sizes at $L=5 \mathrm{~cm}$ (Fig. 2c).

Air pressure is employed at industrial scale to control the droplet size produced by bi-fluid nozzles, as it is expected to have the greatest influence on the atomisation process. Indeed, the acquired experimental results confirm a drastic decrease in droplet size of all sprayed liquids except SMC1 when raising the air pressure between 0.5 and $1.5 \mathrm{bar}$, whereas between 1.5 and $2.5 \mathrm{bar}$, the influence of air pressure was related to the liquid viscosity value: at low viscosity (MS1, MS2, SMC1), sprayed droplets became slightly larger at higher air pressure, whereas at high viscosity (MS3, MS4, SMC2, SMC3), droplet size still decreased over 1.5 bar, especially close to the nozzle. This denotes a complex interaction between liquid physicochemistry (especially viscosity) and operating conditions (mainly, air velocity at the nozzle outlet), leading to an unobvious evolution of droplet size, which strongly depends on the distance to the nozzle. The strong impact of the 

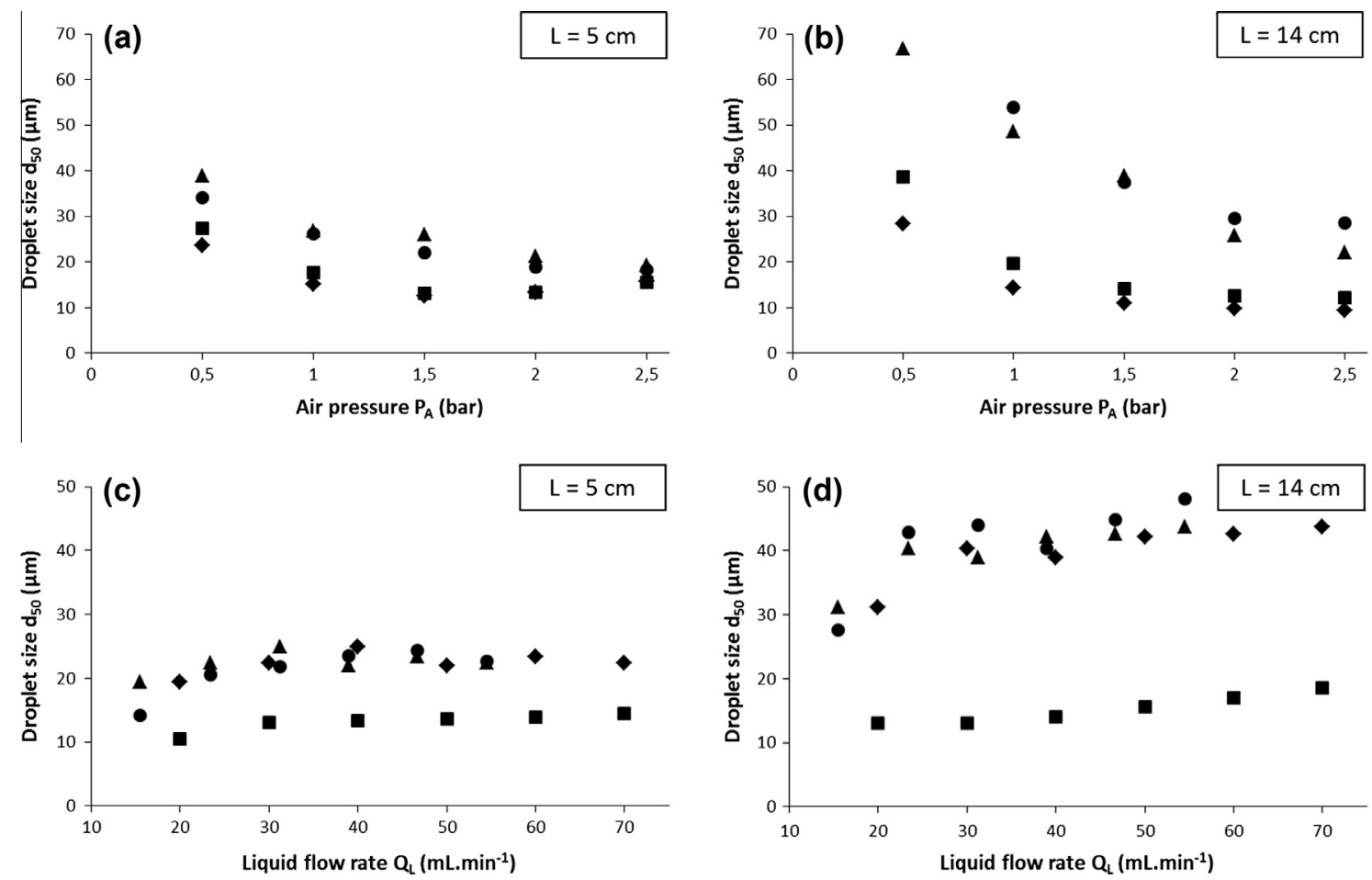

Fig. 1. Droplet size of model solutions at various air pressures and $Q_{L}=31.2 \mathrm{~mL} \mathrm{~min}^{-1}$ for MS3 and MS4 or $40 \mathrm{~mL} \mathrm{~min}^{-1}$ for MS1 and MS2 (a and b) and at various liquid flow rates and $P_{A}=1.5$ bar (c and d), the distance to the nozzle being either equal to $5 \mathrm{~cm}$ (a and c) or $14 \mathrm{~cm}$ (b and d). Squares: MS1; diamonds: MS2; circles: MS3; triangles: MS4.
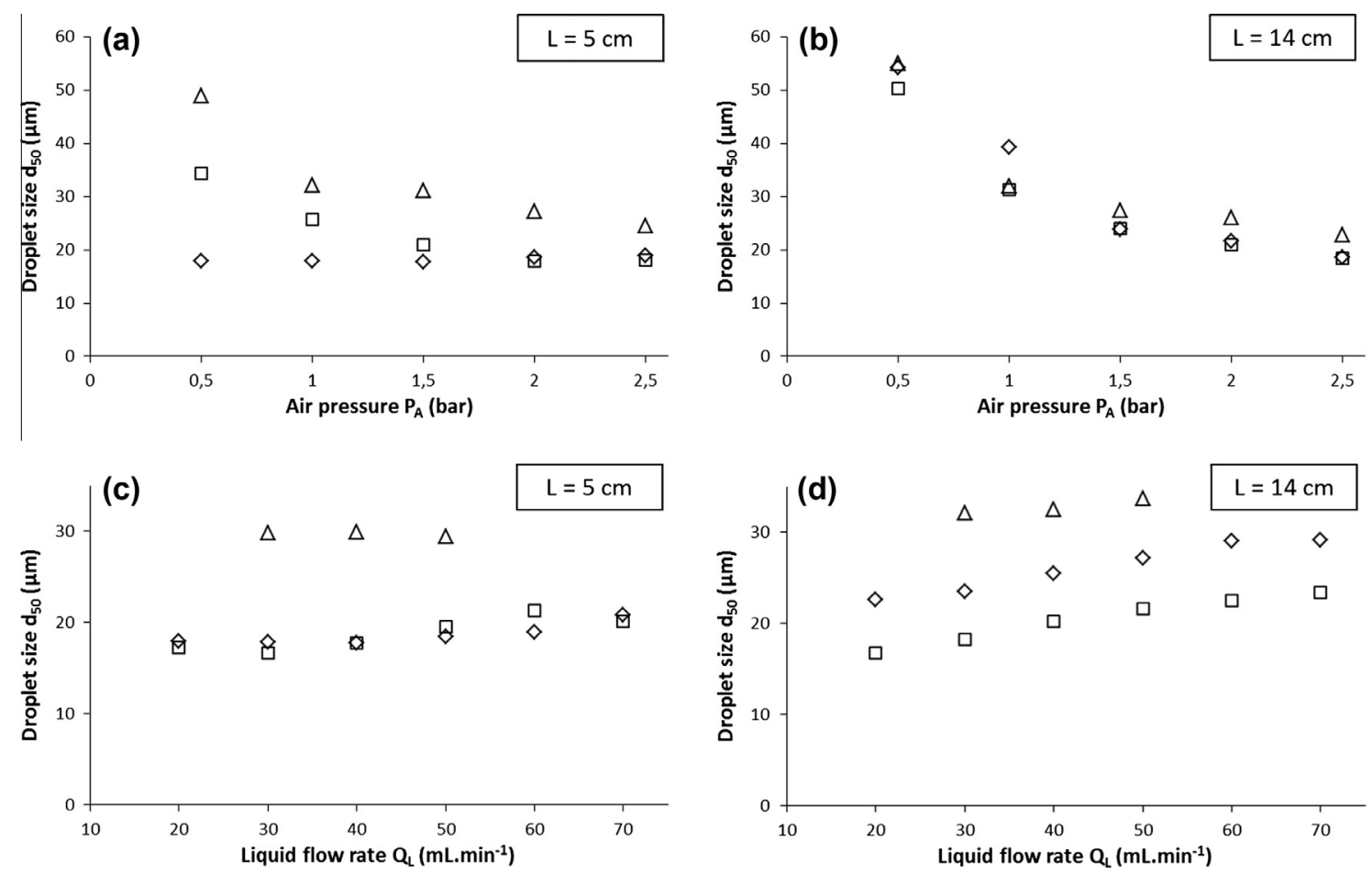

Fig. 2. Droplet size of skimmed milk concentrates for various air pressures at $Q_{L}=40 \mathrm{~mL} \mathrm{~min}{ }^{-1}$ (a and b) and liquid flow rates at $P_{A}=1.5$ bar (c and d), the distance to the nozzle being either equal to $5 \mathrm{~cm}$ ( $a$ and $c)$ or $14 \mathrm{~cm}$ (b and d). Empty squares: SMC1; empty diamonds: SMC2; empty triangles: SMC3.

distance to the nozzle on the involved mechanisms and thus on the role of air pressure in the droplet size is well illustrated by the fact that air pressure seems to have more effect on the droplet size of model solutions at $L=14 \mathrm{~cm}$ than at $L=5 \mathrm{~cm}$, while it induced less changes in the droplet size of skimmed milk concentrates at $L=14 \mathrm{~cm}$ than at $L=5 \mathrm{~cm}$.
3.1.3. Influence of the distance to the nozzle in the atomisation process Both the marked increase in droplet size between $L=5$ and $14 \mathrm{~cm}$ (cf. Figs. 1 and 2), which could not be explained by the single atomisation mechanism (as the atomisation mechanism leads to liquid forms of decreasing size with time, i.e. when the liquid forms move away from the nozzle), and the increased influence of 
physicochemistry far from the nozzle outlet put in evidence the contribution to droplet shaping of a mechanism driven by liquid physicochemistry. This additional mechanism counteracts the atomisation mechanism and becomes even predominant from a certain distance to the nozzle, leading to the observed reincrease in droplet size. From literature knowledge, it appears that droplet sorting, owing to velocity and size differences (Marmottant, 2001), and droplet coalescence after collision (Ehlers et al., 2010) are both good candidates for the additional mechanism identified in the current study, as they induce droplet growing and result from complex interactions between liquid physicochemistry (viscosity, surface tension, etc.) and operating conditions (air-liquid velocity difference, flow regimes in air and liquid, etc.). In the performed experiments, it was shown that the droplet size increase between $L=5$ and $14 \mathrm{~cm}$ was even more pronounced for model solutions than for skimmed milk concentrates, which could be an indication that the evidenced additional mechanism was droplet coalescence. Indeed, surface tension, which is a crucial parameter in the mechanism of droplet coalescence, varied in model solutions but remained almost constant in skimmed milk concentrates.

The interpretation of raw experimental results did not allow further concluding about the combined effect of physicochemistry and operating conditions; it will be shown in the next section that a modelling approach, such as DA, can be used to uncouple their respective influence and identify the key process parameter in the atomisation process (Delaplace et al., 2014).

\subsection{Modelling the influence of process parameters in the atomisation process by $D A$}

This part of the work presents the modelling of the atomisation process following a DA approach, with the aim to gather in single process relationship the influence of the key process parameters identified in Eq. (7) on the droplet size: operating conditions, liquid physicochemistry, and distance to the nozzle.

\subsubsection{Suitability of DA to model the atomisation process}

Model coefficients of Eq. (9) were identified by the method detailed in Section 2.4.4 on the basis of the 134 points of the experimental setup presented in Sections 3.1 and 3.2. They were reported in Table 2, as well as the p-values of statistical analysis. This global model can also be represented by the obtained dimensionless process relationship (Eq. (11)):

$$
\frac{d_{50}}{L}=1.37 \times 10^{-9}\left(\frac{\varphi_{L}}{L}\right)^{0.76}\left(\frac{\mu_{L}}{\mu_{A}}\right)^{0.02}\left(\frac{\rho_{L}}{\rho_{A}}\right)^{2.90} B 0^{0.44} W e^{-0.42} A L R^{-0.19}
$$

Also, Table 2 displays the coefficient of determination $R^{2}$, representing the model accuracy (i.e. goodness of fit), and the mean and maximal absolute relative errors (respectively, MARE and $A R E_{\max }$ ) of Eq. (11) with respect to the experimental setup. Model accuracy of Eq. (11) was also gauged with Fig. 3a, which compares model and experimental values of $\pi_{T}=\frac{d_{50}}{L}$. This model was also validated on 14 unknown samples, represented in full symbols in Fig. 3a, and the associated NMRSE was given in Table 2.

Statistical analysis showed that all dimensionless numbers were significant for explaining the variation of $\pi_{T}$ ( $p$-value $\left.<0.05\right)$, except $a_{2}$, which suggests that the dimensionless liquid viscosity did not significantly affect the droplet size. This is in contradiction with the interpretation of raw experimental results (cf. Section 3.1.1), where a clear influence of liquid viscosity was denoted. This indicates that the chosen mathematical model (monomial form of Eqs. (9) and (11)) failed to describe with enough precision the effect of each influent variable on the droplet size, when simultaneously considering droplet sizes measured close and far from
Table 2

Model coefficients of Eqs. (11)-(13), statistical analysis, and model validation parameters.

\begin{tabular}{|c|c|c|c|}
\hline & $\begin{array}{l}\text { Global model } \\
\text { (Eq. (11)) }\end{array}$ & $\begin{array}{l}\text { Model adapted to } \\
L=5 \mathrm{~cm} \text { (Eq. (12)) }\end{array}$ & $\begin{array}{l}\text { Model adapted to } \\
L=14 \mathrm{~cm} \text { (Eq. (13)) }\end{array}$ \\
\hline \multicolumn{4}{|c|}{ Model coefficients (associated dimensionless numbers) and statistical analysis } \\
\hline$a_{0}$ & $1.37 \times 10^{-9 \dagger}$ & $4.08 \times 10^{1 \dagger}$ & $3.96 \times 10^{-23 \dagger}$ \\
\hline$a_{1}\left(\frac{\varphi_{L}}{L}\right)$ & $0.76^{*}$ & 0 & 0 \\
\hline$a_{2}\left(\frac{\mu_{L}}{\mu_{A}}\right)$ & 0.02 & $0.16^{\dagger}$ & $-0.13^{\dagger}$ \\
\hline$a_{3}\left(\frac{\rho_{L}}{\rho_{A}}\right)$ & $2.90^{\dagger}$ & $-1.45^{\ddagger}$ & $7.24^{\dagger}$ \\
\hline$a_{4}(B o)$ & $0.44^{*}$ & $0.25^{\dagger}$ & $0.63^{*}$ \\
\hline$a_{5}(W e)$ & $-0.42^{*}$ & $-0.29^{*}$ & $-0.56^{*}$ \\
\hline$a_{6}(A L R)$ & $-0.19^{\dagger}$ & $-0.17^{\dagger}$ & $-0.22^{\dagger}$ \\
\hline$R^{2}$ & $77 \%$ & $78 \%$ & $81 \%$ \\
\hline \multicolumn{4}{|l|}{ Model validation } \\
\hline NMRSE & $17 \%$ & - & - \\
\hline$N M R S E_{L=5} \mathrm{~cm}$ & $18 \%$ & $15 \%$ & - \\
\hline$N M R S E_{L}=14 \mathrm{~cm}$ & $15 \%$ & - & $13 \%$ \\
\hline MARE & $13 \%$ & - & - \\
\hline$M A R E_{L}=5 \mathrm{~cm}$ & $12 \%$ & $11 \%$ & - \\
\hline$M A R E_{L}=14 \mathrm{~cm}$ & $15 \%$ & - & $11 \%$ \\
\hline$A R E_{\max } ; L=5 \mathrm{~cm}$ & $31 \%$ & $23 \%$ & - \\
\hline$A R E_{\max }$ & $29 \%$ & - & $17 \%$ \\
\hline \multicolumn{4}{|l|}{$L=14 \mathrm{~cm}$} \\
\hline $\begin{array}{l}\text { Not determinec } \\
p<0.0001 \\
0.0001<p<0.05 \\
p>0.05 .\end{array}$ & & & \\
\hline
\end{tabular}

the nozzle outlet. However, considering the difficulty to perform experimental measurements of the size of sprayed droplets in atomisation processes, the goodness of fit was satisfactory, owing to the correct value of $R^{2}(77 \%)$, and it can be seen in Fig. 3a that most (about 94 out of 134) of the experimental points were modelled within $20 \%$ relative error. Moreover, the model accuracy was correct, as MARE and $A R E_{\max }$ values were moderate: respectively, $13 \%$ and $31 \%$. Thus, it can be considered that Eq. (11) allows a correct description of the evolution of the droplet size with respect to the main process parameters, except for liquid viscosity.

Model validation was achieved on 14 unknown samples (corresponding to repetitions of central points of the experimental setup), and it can be seen in Fig. 3a that Eq. (11) permitted to predict the droplet size of 9 unknown samples within 20\% accuracy, which is satisfactory, owing to the large ranges of investigated process parameters ( 7 sprayed liquids, 2 distances to the nozzle, and multiple values of air pressures and liquid flow rates). Besides, the NMRSE (cf. Table 2) calculated on the basis of the predicted dimensionless droplet sizes of unknown samples, was equal to $17 \%$, which is a little high but remains correct; this was illustrated in Fig. 3a by the fact that the majority (11 out of 14) of droplet sizes of unknown samples were predicted within $20 \%$ accuracy.

In conclusion, the dimensionless model of Eq. (11) permitted to correctly describe the variation trend of droplet size according to the process parameters identified in Eq. (7) and predict the droplet size of unknown samples, but it did not well represent the influence of each process parameter on the droplet size, as liquid viscosity seemed not to be influential. This last point can be related to the complex influence of viscosity, interacting with other process parameters such as surface tension and operating conditions, which was evidenced in Section 3.1.1.

In order to address this shortcoming of Eq. (11), improve the model accuracy, and establish dimensionless process relationships permitting to understand the role of process parameters in the atomisation mechanism, it was decided to adapt the DA model to each value of distance to the nozzle, as the predominant mechanisms may change with the distance to the nozzle. Indeed, the experimental results of Section 3.1 showed that the atomisation mechanism may predominate close to the nozzle outlet, whereas 

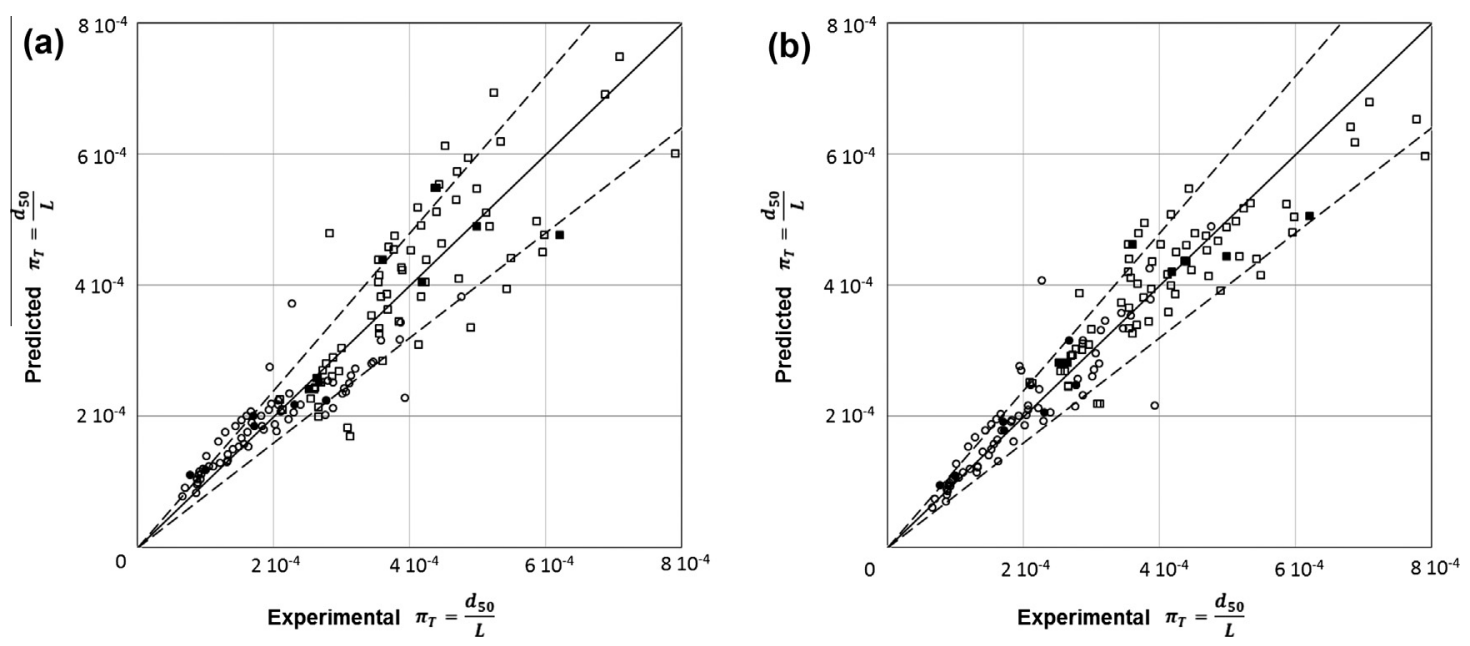

Fig. 3. Comparison between the experimental and modelled values of dimensionless droplet sizes. (a) General model (Eq. (10)); (b) restricted models (Eqs. (11) and (12)). Full and empty squares respectively represent droplet size at $L=5$ and $14 \mathrm{~cm}$. The straight line of unity slope corresponds to equal experimental and model values. Dashed lines stand for model errors of $\pm 20 \%$.

far from the nozzle outlet the atomisation mechanism was probably counteracted by droplet coalescence. The distance to the nozzle being fixed for models restricted to a single $L$ value, $\pi_{1}$ was fixed (cf. Eqs. (8) or (9) with a constant $L$ value) and could be removed from the set of dimensionless numbers. By using this reduced set of dimensionless numbers, the coefficients of these restricted models were determined with the method presented in Section 2.4.4 on the 67 points acquired at each distance to the nozzle, and the following process relationships were obtained (Eqs. (12) and (13)):

$$
\begin{aligned}
\bullet & =5 \mathrm{~cm}: \\
\frac{d_{50}}{L} & =4.08 \times 10^{1}\left(\frac{\mu_{L}}{\mu_{A}}\right)^{0.16}\left(\frac{\rho_{L}}{\rho_{A}}\right)^{-1.45} B 0^{0.25} W e^{-0.29} A L R^{-0.17} \\
\bullet & =14 \mathrm{~cm}: \\
\frac{d_{50}}{L} & =3.96 \times 10^{-23}\left(\frac{\mu_{L}}{\mu_{A}}\right)^{-0.13}\left(\frac{\rho_{L}}{\rho_{A}}\right)^{7.24} B 0^{0.63} W e^{-0.56} A L R^{-0.22}
\end{aligned}
$$

As for the general model, model accuracy was evaluated by goodness of fit and relative errors (Table 2). Also, each restricted model was validated by calculating the NMRSE on the 7 unknown samples acquired at each distance to the nozzle (Table 2). The comparison between experimental and modelled dimensionless droplet size was achieved in Fig. $3 \mathrm{~b}$, where the predicted values for unknown samples were also represented.

It can be noticed that this adaptation of the general DA model to each distance to the nozzle allowed a slight increase in model accuracy, as higher $R^{2}$ values were obtained (respectively $78 \%$ and $81 \%$ for Eqs. (12) and (13)) and more points (about 110 out of 134 ) were found within the $\pm 20 \%$ relative error range in Fig. 3b. Also, Table 2 shows that Eqs. (12) and (13) permitted to lower the absolute relative errors to a mean value of about $11 \%$ and a maximal value of $23 \%$, in comparison to the general model. The improvement of model accuracy is even higher with Eq. (13), as attested by the lower MARE and $A R E_{\max }$ values calculated on the 67 experimental results obtained at $L=14 \mathrm{~cm}$.

Statistical analysis of model coefficients associated with Eqs. (12) and (13) showed that all considered process parameters were significant in the evolution of the droplet size, except for the liquid density at $L=5 \mathrm{~cm}(p$-value $=0.15)$. The negligible influence of liquid density close to the nozzle was not surprising, as literature reports that the influence of liquid density in the atomisation mechanism has not been clearly evidenced. Also, it was expected (from literature review and experimental results of the current study) that, close to the nozzle outlet like at $L=5 \mathrm{~cm}$, the droplet size is controlled by operating conditions through the atomisation mechanism, instead of liquid physicochemistry. The validation of restricted models on unknown samples will help to judge the suitability of these models for predicting droplet sizes in the investigated ranges of process parameters.

Restricted models were validated by the lower NMRSE obtained with unknown samples, in comparison with the general model: at $L=5 \mathrm{~cm}$, the $\operatorname{NMRSE}_{L}=5 \mathrm{~cm}$ was decreased from $18 \%$ with Eq. (11) $15 \%$ with Eq. (12), whereas at $L=14 \mathrm{~cm}$, the $N M R S E_{L}=14 \mathrm{~cm}$ was decreased from $15 \%$ with Eq. (11) to $13 \%$ with Eq. (12). Also, more (12 out of 14) droplet sizes of unknown samples were predicted within $20 \%$ accuracy, confirming the better suitability of restricted models for predicting droplet sizes formed in the atomisation process.

\subsubsection{Respective influences of process parameters in the atomisation} process

The influence of process parameters will be exclusively discussed from the restricted models, as the general model was less accurate and led to a negligible influence of liquid viscosity in disagreement with experimental results and literature knowledge.

On one hand, it can be seen that the signs of model coefficients were identical at both distances to the nozzle, except for $a_{2}$ associated with $\frac{\mu_{L}}{\mu_{A}}$ and $a_{3}$ associated with $\frac{\rho_{L}}{\rho_{A}}$. This implies that a unique mechanism (the atomisation one) stays predominant with regard to droplet size in the whole range of investigated process parameters, but also that the roles of liquid viscosity and density in the droplet size changes far from the nozzle outlet. Indeed, the contribution of the coalescence mechanism affects the role of liquid viscosity at $L=14 \mathrm{~cm}$, as viscosity is both opposed to liquid jet break-up, leading to size decrease (Marmottant, 2001), and droplet coalescence, inducing size increase (Podgorska, 2007). The same interpretation can be done for liquid density, as it appeared from literature review that compact sprays are formed with high density liquids, lowering the efficiency of the atomisation mechanism, and high density liquids are less prone to coalesce, as too much inertial energy of impacting droplets reduces the coalescence efficiency (Corral, 2011). 


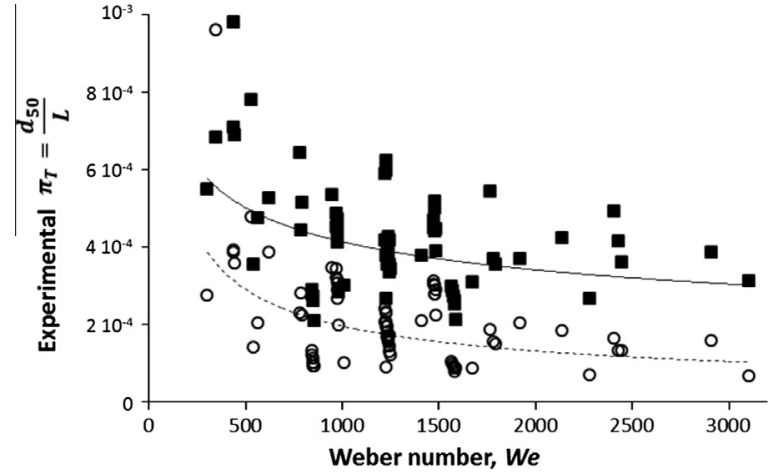

Fig. 4. Evolution of the dimensionless droplet size of the experimental set-up and unknown samples with the aerodynamic Weber number. Full squares and empty circles respectively represent the droplet sizes at $L=5$ and $14 \mathrm{~cm}$. Straight and dashed lines correspond to power law regressions (respectively, Eqs. (14) and (15)).

On the other hand, the absolute values of model coefficients of Eqs. (12) and (13) (cf. Table 2) can be used to have a general overview of the importance of process parameters in droplet shaping: the higher the absolute value of a model coefficient, the stronger the influence of the process parameters involved in the associated dimensionless number. Operating conditions (associated with We and $A L R$ ) impacted more on the droplet size than liquid viscosity and surface tension (related to $\frac{\mu_{L}}{\mu_{A}}$ and $B o$ ), but, surprisingly, less than liquid density (cf. $\frac{\rho_{L}}{\rho_{A}}$. This latter assertion has to be qualified, as liquid density was involved in several dimensionless numbers of Eqs. (12) and (13), and thus its influence cannot be totally understood from model coefficients. Comparing the absolute values of model coefficients of Eqs. (12) and (13) allowed to deduce how the respective influences of liquid physicochemistry and operating conditions on the droplet size are affected by the distance to the nozzle. Indeed, the model coefficient associated with $A L R$ (involving only operating conditions) was similar at $L=5$ and $14 \mathrm{~cm}$, whereas model coefficients corresponding to dimensionless numbers involving only the liquid physicochemical properties $\left(\frac{\mu_{L}}{\mu_{A}}, \frac{\rho_{L}}{\rho_{A}}\right.$, and Bo $)$ increased or remained similar when increasing the distance to the nozzle. It can be deduced that liquid physicochemistry influenced more the atomisation process far from the nozzle, which is consistent with the presupposed contribution of the coalescence mechanism in the droplet size between $L=5$ and $14 \mathrm{~cm}$. Last, it should be added that the rather high absolute values of the model coefficient of aerodynamic Weber number We in Eqs. (12), (13) shows that this dimensionless number, linking the driving force of liquid jet break-up (operating conditions) to the resistance of the liquid to deformation (liquid physicochemistry), is of prime importance to control the size of sprayed droplets. Fig. 4 was drawn to illustrate this major importance of the aerodynamic Weber number in the atomisation process. It represents the evolution trends of dimensionless droplet sizes with $W e$, as well as power law regressions of the dependency of the dimensionless droplet sizes to We at each distance to the nozzle (Eqs. (14), (15)).

$$
\begin{aligned}
& -L=5 \mathrm{~cm}: \\
& \frac{d_{50}}{L}=2.82 \times 10^{-3} W e^{-0.28} \\
& \bullet L=14 \mathrm{~cm}: \\
& \frac{d_{50}}{L}=1.00 \times 10^{-2} W e^{-0.57}
\end{aligned}
$$

These power law regressions were obviously of low accuracy $\left(R^{2}=15 \%\right.$ and $26 \%$ respectively for Eqs. (14) and (15)), as they involved only one relevant dimensionless number associated to process parameters $(W e)$. However, they were consistent with the model coefficients obtained through the DA modelling approach (cf. Eqs. (12), (13)), confirming the suitability of the developed restricted models and the predominance of the aerodynamic Weber number in the atomisation process whatever the distance to the nozzle.

In Fig. 4, the dimensionless droplet size decrease with We and the lower scattering of dimensionless droplet size around the curves representing Eqs. (14) and (15) at higher We confirmed the control of droplet size by operating conditions at both distances to the nozzle, owing to the predominance of the atomisation mechanism. The greater influence of the aerodynamic Weber number at $L=14 \mathrm{~cm}$ was also an indication that the role of surface tension in droplet shaping was enhanced between $L=5$ and $14 \mathrm{~cm}$ (as $\sigma$ is equally involved in the expression of We, cf. Eq. (4)), in compliance with the increasing importance of the coalescence mechanism when droplets move away from the nozzle.

\section{Conclusions}

This paper allowed showing that the atomisation of skimmed milk concentrates follows the general atomisation mechanism described in the literature for bi-fluid nozzles, in which the driving force of liquid jet break-up is controlled by operating conditions and the resistance to break-up is related to the physicochemistry of the sprayed liquid. Close to the nozzle, it was shown that the droplet size is mainly controlled by the conditions of liquid jet break-up (air velocity and liquid viscosity), in accordance with the atomisation mechanism evidenced by previous works in the literature. Interestingly, it was found that droplets were larger further from the nozzle outlet, which indicated the occurrence of an additional mechanism counteracting the atomisation one and leading to droplet size increase: droplet coalescence.

The second part of the study presented a DA modelling approach of liquid atomisation, which aimed at clarifying the respective roles of operating conditions, liquid physicochemistry, and distance to the nozzle in droplet formation and determining how the atomisation process was influenced by the coalescence mechanism. It was shown that air and liquid velocities should be considered in droplet size models instead of the more common air pressure and liquid flow rate, as these velocities, integrating both geometrical and energetic aspects of the atomisation operation, permitted to reduce the set of relevant dimensionless numbers and give rise to the key dimensionless numbers of the atomisation mechanism, namely the aerodynamic Weber number and the air-to-liquid flow rate ratio. Also, the suitability of DA for modelling the droplet size was demonstrated, provided that the determination of model coefficients was adapted to the distance to the nozzle, as it was highlighted a change in the involved mechanisms according to the distance to the nozzle: either atomisation only close to the nozzle outlet or atomisation followed by droplet coalescence at longer distances. Finally, the prime importance of the Weber aerodynamic number in the atomisation process was emphasised.

\section{Role of the funding source}

The partners in the ANR project ANR-08-ALIA-15 took part in the decision to submit this manuscript for publication.

\section{Acknowledgements}

This work was carried out within the framework of the Reactive Powder project ANR-08-ALIA-15. The authors wish to thank Samuel Janin, Master student at Agrocampus Ouest at the time of 
the study, for his contribution to viscosity analyses, as well as their partners in the Reactive Powder project, for the stimulating scientific discussions. Moreover, the authors address a special acknowledgement to the anonymous manuscript reviewers for their helpful advices regarding the mathematical modelling approach.

\section{References}

Beau, P.A., 2006. Modélisation de l'atomisation d'un jet liquide - Application aux sprays diesel. PhD thesis, Université de Rouen, France.

Buckingham, E., 1914. On physically similar systems: Illustrations of the use of the dimensional equations. Phys. Rev. 4, 345-376.

Chigier, N.A., 1976. The atomisation and burning of liquid fuel sprays. Prog. Energy Combust. Sci. 2, 97-114.

Corral, M. Jr., 2011. Controlling Drop Coalescence Using Nano-engineered Surfaces. B. Eng. Thesis, Massachussets Institute of Technology, USA.

Cuq, B., Gaiani, C., Turchiuli, C., Galet, L., Scher, J., Jeantet, R., Mandato, S., Petit, J., Murrieta-Pazos, I., Barkouti, A., Schuck, P., Rondet, E., Delalonde, M., Dumoulin, E., Delaplace, G., Ruiz, T., 2013. Advances in food powder engineering. In: Henry, Jeyakumar (Ed.), Advances in Food and Nutrition Research, vol. 69. Academic Press, Burlington, pp. 41-103, ISBN: 978-0-12-410.

Delaplace, G., Coppenolle, P., Cheio, J., Ducept, F., 2012. Influence of whip speed ratios on the inclusion of air into a bakery foam produced with a planetary mixer device. J. Food Eng. 108, 532-540.

Delaplace, G., Ducept, F., Jeantet, R., Loubière, K., 2014. Modélisation en Génie des Procédés par analyse dimensionnelle. Tec \& Doc, Lavoisier, Paris. ISBN: 9782743015701, p. 443.

Ehlers, H., Larjo, J., Antikainen, O., Räikkönen, H., Heinämäki, J., Yliruusi, J., 2010. In situ droplet size and speed determination in a fluid-bed granulator. Int. J. Pharm. 391, 148-154.

Ejim, C.E., Rahman, M.A., Amirfazli, A., Fleck, B.A., 2010. Effects of liquid viscosity and surface tension on atomization in two-phase, gas/liquid fluid coker nozzles. Fuel 89, 1872-1882. http://dx.doi.org/10.1016/j.fuel.2010.03.005.

Faragó, Z., Chigier, N., 1992. Morphological classification of disintegration of round liquid jets in a coaxial air stream. Atom. Sprays 2, 137-153.

Hager, W.H., 2012. Wilfried noel bond and the bond number. J. Hydraul. Res. 50, 39.

Hassan, R., Loubière, K., Legrand, J., Delaplace, G., 2012. A consistent dimensional analysis of gas-liquid mass transfer in a volume aerated stirred tank containing purely viscous fluids with shear-thinning properties. Chem. Eng. J. 184 42-56.

Hede, P.D., Bach, P., Jensen, A.D., 2008a. Two-fluid spray atomisation and pneumatic nozzles for fluid bed coating/agglomeration purposes: a review. Chem. Eng. Sci. 63, 3821-3842

Hede, P.D., Bach, P., Jensen, A.D., 2008b. Top-spray fluid bed coating: scale-up in terms of relative droplet size and drying force. Powder Technol. 184, 318-332.
Iveson, S.M., Litster, J.D., Hapgood, K., Ennis, B.J., 2001. Nucleation, growth and break-up phenomena in wet granulation processes: a review. Powder Technol. $117,3-39$.

Jeantet, R., Roignant, M., Brulé, G., 2001. Génie des procédés appliqué à l'industrie laitière. Tec \& Doc, Lavoisier, Paris, p. 164.

Jimenez-Munguia, M.T., 2007. Agglomération de particules par voie humide en lit fluidisé. PhD thesis, Ecole Nationale Supérieure des Industries Agricoles et Alimentaires, Massy, France.

Juslin, L., Antikainen, O., Merkku, P., Yliruusi, J., 1995. Droplet size measurement: I. Effect of three independent variables on droplet size distribution and spray angle from a pneumatic nozzle. Int. J. Pharm. 123, 247-256.

Lefebvre, A.H., 1980. Airblast atomisation. Prog. Energy Combust. Sci. 6, $233-261$.

Leuenberger, H., Betz, G., Jones, D.M., 2006. Chapter 8: Scale-up in the field of granulation and drying. In: Michael Levin (Ed.), Pharmaceutical process scaleup, second ed. Taylor \& Francis, New York, USA.

Litster, J.D., Ennis, B.J., 2004. The Science and Engineering of Granulation Processes. Kluwer Academic Publishers, Powder Technology Series, Dordrecht, the Netherlands.

Mandato, S., Rondet, E., Delaplace, G., Barkouti, A., Galet, L., Accart, P., Ruiz, T., Cuq, B., 2012. Liquids' atomization with two different nozzles: modelling of the effects of some processing and formulation conditions by dimensional analysis. Powder Technol. 224, 323-330.

Marmottant, P., 2001. Atomisation d'un liquide par un courant gazeux. PhD thesis, Institut National Polytechnique de Grenoble, France.

Nguyen, D.A., Rhodes, M.J., 1998. Producing fine drops of water by twin-fluid atomisation. Powder Technol. 99, 285-292.

Nukiyama, S., Tanasawa, Y., 1939. Experiments on the atomisation of a liquid in an airstream. Trans. Jpn. Soc. Mech. Eng. 5, 68-75.

Parikh, D.M, 2006. Chapter 9: batch size increase in fluid-bed granulation. In: Michael Levin (Ed.), Pharmaceutical process scale-up, second ed. Taylor \& Francis, New York, USA.

Petit, J., Six, T., Moreau, A., Ronse, G., Delaplace, G., 2013. $\beta$-lactoglobulin denaturation, aggregation, and fouling in a plate heat-exchanger: pilot-scale experiments and dimensional analysis. Chem. Eng. Sci. 101, 432-450.

Podgorska, W., 2007. Influence of dispersed phase viscosity on drop coalescence in turbulent flow. Trans. IChemE - Part A: Chem. Eng. Res. Des. 85 (A5), 721-729.

Saad, M., 2011. Etude des mécanismes d'agglomération des poudres céréalières: contribution des caractéristiques physiques et chimiques des particules à leur réactivité. Application à la fabrication du couscous. PhD thesis, Centre International d'Etudes Supérieures en Sciences Agronomiques de Montpellier SupAgro, France.

Vaschy, A., 1892. Sur les lois de similitude en physique. Annales Télégraphiques. 19, 25-28.

White, F.M., 1991. Viscous fluid flow, second ed. McGraw-Hill, New York, USA, p. 614, ISBN: 0-07-069712-4.

Zlokarnik, M., 2006. Scale-up in Chemical Engineering, second ed. Wiley-VCH Verlag GmbH \& Co. KGaA, Weinheim, Germany, p. 270. 